\title{
PERAN SELF-REGULATED LEARNING DALAM MEMODERATORI PEMBELAJARAN DENGAN PENDEKATAN SAINTIFIK TERHADAP HASIL BELAJAR SISWA
}

\author{
Fika Widya Pratama \\ fika.pratama@staff.uksw.edu \\ Program Studi Pendidikan Matematika \\ FKIP - Universitas Kristen Satya Wacana Salatiga
}

\begin{abstract}
The purpose of this research was to know whether or not Self-Regulated Learning (SRL) plays on important role in moderating learning based on scientific approach toward student learning outcomes at grade VII A in SMP $N 3$ Sawit, Boyolali regency. This research is an experimental research with factorial design. The initial data with normal distribution was used with Kolmogorov-Smirnov test. After that, the Regression Analysis (RA) and Moderated Regression Analysis (MRA) was also conducted. The result of this research contributed $18.2 \%$, it increased from $21.4 \%$ to $39.6 \%$. So, SRL gave positive effect in scientific approach based learning to students learning outcomes because the students had learning initiatives, learning resolution, and were able to solve the problems. This research is expected to give contribution of knowledge for teachers about SRL which can give positive effects for students in scientific approach based learning.
\end{abstract}

Keywords: Classical learning, scientific approach, Self-Regulated Learning (SRL), student learning outcomes.

\section{PENDAHULUAN}

Mata pelajaran matematika merupakan salah satu mata pelajaran yang ada di setiap jenjang pendidikan, baik di jenjang pendidikan dasar, menengah, atas maupun kejuruan. Mata pelajaran matematika juga sangat penting dalam kehidupan sehari-hari, contohnya dalam hal berdagang untuk menghitung untung-rugi sampai dengan perencanaan kedepannya. Tidak hanya itu, matematika juga merupakan dasar dari ilmu lain seperti fisika, kimia, dan ekonomi. Belajar matematika dapat membentuk pola pikir yang sistematis, mengembangkan logika berpikir, menjadikan lebih kritis, dan kreatif. Sejalan dengan itu, Cockroft (dalam Hadi 2010) menyatakan bahwa perlunya peserta didik belajar matematika dengan alasan bahwa matematika merupakan alat komunikasi yang sangat kuat, teliti, dan pasti. Pembelajaran matematika itu sendiri dapat membantu menciptakan sumber daya manusia yang berkualitas. Oleh karena itu diupayakan pengelolaan pendidikan dan strategi yang baik agar dapat menciptakan sumber daya manusia yang berkualitas, cerdas, kreatif, kritis, dan inovatif.

Kenyataannya, pembelajaran matematika belum mendapatkan hasil yang optimal. Hal ini terlihat dalam hasil Ujian Nasional (UN) SMP negeri yang diperoleh dari data daya serap (dari Badan Standar Nasional Pendidikan). Diperoleh data tentang rerata nilai UN matematika di-Kabupaten Boyolali mengalami penurunan yaitu dari 6.83 (tahun ajaran 2011/2012) menjadi 5.42 (tahun ajaran 2012/2013). Tidak hanya itu, rerata nilai UN matematika berada di bawah rerata IPA (5.73) 
dan Bahasa Indonesia (7.66). Tahun ke tahun, rerata nilai UN matematika berada di bawah rerata nilai pelajaran lainnya, seperti pada tahun ajaran 2013/2014 rerata nilai UN diKabupaten Boyolali hanya 5.59 lebih rendah dari rerata nilai UN di tingkat jawa tengah (yaitu 5.63) dan di tingkat nasional (yaitu 6.10). Hal ini menunjukan bahwa pembelajaran matematika di Kabupaten Boyolali masih belum optimal. Salah satu cara untuk meningkatkan hasil pembelajaran matematika dan menciptakan sumber daya manusia yang berkualitas, cerdas, kreatif, kritis, dan inovatif ialah dengan melalui penerapan kurikulum 2013.

Dalam Permendikbud Nomor 81a 2013 Lampiran IV tentang implementasi kurikulum, proses pembelajaran pada kurikulum 2013 ini terdiri dari 5M yaitu mengamati, menanya, mengumpulkan data, menganalisis, dan mengkomunikasikan. Proses pembelajaran ini menggunakan pendekatan saintifik yang menuntut siswa untuk dapat belajar aktif sehingga mengubah yang dulunya teacher centered menjadi student centered. Sebagai bentuk implementasi dari kurikulum 2013 pengelolaan pembelajaran dari model menggunakan pendekatan saintifik yang menyentuh tiga ranah yaitu sikap, pengetahuan, dan keterampilan. Model-model yang ditawarkan cukup beragam, ada Discovery Learning, Problem Based Learning, Project Based Learning, Cooperative learning, dan lain-lain. Pembelajaran saintifik yang dipakai adalah pembelajaran klasikal dengan pendekatan saintifik. Penelitian ini menerapkan pembelajaran klasikal dengan pendekatan saintifik yang memuat 5M. Proses pembelajaran dalam implementasi kurikulum 2013 mengharuskan para guru untuk mengubah main set yang semula teacher center menjadi student center.
Hosnan (2014) mengemukakan dalam kurikulum 2013, selain menumbuh dan mengembangkan sikap, pengetahuan, dan keterampilan, kualitas yang dikembangkan kurikulum dan harus terealisasikan dalam proses pembelajaran, antara lain kreativitas, kemandirian, kerja sama, solidaritas, kepemimpinan, empati, toleransi, dan kecakapan hidup peserta didik guna membentuk watak serta meningkatkan peradaban dan martabat bangsa. Sejalan dengan itu, Sumarmo (2010) istilah kemandirian belajar sering berhubungan dengan beberapa istilah diantaranya self regulated learning, self regulated thinking, self direct learning, self efficacy dan self esteem. Kelima istilah tersebut tidak sama tepat namun mempunyai beberapa karakteristik. Untuk menghindarkan salah pengertian, kemandirian belajar disini akan diterjemahkan sebagai self regulated learning (SRL).

Siswa dengan SRL dalam proses pembelajarannya dapat memberikan dampak yang kuat terhadap kesadaran dalam proses pembelajaran: pengetahuan, kepercayaan, dan pendapat tetang pembelajaran dan beberapa hal yang berdampak pada proses pembelajaran (Ferla, 2008). Sedangkan Vrieling (2012) dalam penelitiannya menyatakan bahwa murid akan mengalami pertambahan prestasi yang signifikan di dalam lingkungan pembelajaran dengan adanya peningkatan kemandirian belajar. Paris (2001) dalam penelitiannya menyatakan bahwa SRL sangat bermanfaat dalam pencerminan murid dan metakognitif dalam 3 hal yaitu selama awal pembelajaran, pemecahan kesulitan, dan selama pembelajaran yang menggunakan strategi lain. Sejalan dengan itu, penelitian yang dilakukan Sui dan Ho (2004) menunjukkan bahwa SRL memiliki hubungan yang positif dengan kesuksesan dalam membaca, matematika, dan ilmu alam. 
Dari hasil penelitian yang telah dilakukan, SRL dapat memberikan dampak yang positif dalam kesuksesan pembelajaran matematika serta SRL dibutuhkan dalam proses pembelajaran saintifik. Dari beberapa hasil penelitian di atas, timbul pertanyaan tentang apakah SRL dapat berperan dalam memoderatori pembelajaran dengan pendekatan saintifik terhadap hasil belajar siswa.

\section{KAJIAN PUSTAKA}

\section{Pembelajaran klasikal dengan pendekatan saintifik}

Pembelajaran klasikal (Dimyati dan Mudjiono, 2006:169-170) merupakan kemampuan guru yang utama. Hal itu disebabkan oleh pengajaran klasikal merupakan kegiatan mengajar yang tergolong efisien. Pembe-

Tabel 1 . Langkah-langkah Model Pembelajaran Klasikal dengan Pendekatan Saintifik

\begin{tabular}{|c|c|}
\hline Langkah-Langkah & Kegiatan Pembelajaran \\
\hline Mengamati & $\begin{array}{l}\text { yang berkaitan dengan penggunaan bilanga } \\
\text { atau suhu berbagai benda, ketinggian pohon at } \\
\text { 2. Siswa diberi LKS. }\end{array}$ \\
\hline & $\begin{array}{l}\text { skan atau mengajukan pertanyaan tentang apa yang diamati. } \\
\text { dkan pertanyaan tentang informasi yang kurang jelas tentang } \\
\text { ati untuk mendapatkan informasi tambahan. }\end{array}$ \\
\hline $\begin{array}{l}\text { Mengumpulkan } \\
\text { Informasi }\end{array}$ & $\begin{array}{l}\text { 5. Siswa melakukan eksperimen, membaca sumber lain selain buku teks, } \\
\text { mengamati objek atau kejadian, aktivitas wawancara dengan nara sumber. }\end{array}$ \\
\hline Mengasosiasi & $\begin{array}{l}\text { 6. Siswa mengolah informasi yang sudah dikumpulkan baik terbat } \\
\text { hasil kegiatan mengumpulkan/eksperimen maupun hasil dari } \mathrm{k} \\
\text { mengamati dan kegiatan mengumpulkan informasi. }\end{array}$ \\
\hline $\begin{array}{l}\text { Mengkomu- } \\
\text { nikasikan }\end{array}$ & $\begin{array}{l}\text { 7. Siswa menyampaikan hasil pengamatan dan menyampaikan kesimpulan } \\
\text { berdasarkan hasil analisis secara lisan, tertulis, atau media lainnya. }\end{array}$ \\
\hline \multicolumn{2}{|c|}{$\begin{array}{rll}\text { Self-Regulated Learning (SRL) } & \text { Durkheim } & \text { (dalam Asrori, 2008: 129) } \\
\text { Zumbrunn, et al (2011) menyatakan } & \text { berpendapat bahwa SRL itu tumbuh dan } \\
\text { bahwa SRL adalah proses yang membantu } & \text { berkembang karena adanya dua faktor yaitu } \\
\text { siswa mengelola pikiran mereka, perilaku dan } & \text { adanya disiplin yaitu adanya aturan betindak } \\
\text { emosi agar berhasil menavigasi pengalaman } & \text { dan otoritas dan adanya komitmen terhadap } \\
\text { belajar mereka. Sedang menurut Montalvo dan } & \text { kelompok. Dari beberapa pengertian SRL } \\
\text { Maria (2004) menyatakan SRL merupa-kan } & \text { yang telah dikemukakan, dapat diambil } \\
\text { perpaduan antara keterampilan dan kemauan. } & \text { kesimpulan bahwa SRL adalah suatu } \\
& \text { perubahan dalam diri siswa untuk melakukan }\end{array}$} \\
\hline
\end{tabular}

lajaran klasikal berarti melaksanakan dua kegiatan sekaligus, yaitu pengelolaan kelas dengan menciptakan kondisi kegiatan belajar yang baik serta pengelolaan pembelajaran. Menurut Nasution (dalam Sagala, 2010:185) menyatakan bahwa pembelajaran klasikal mencerminkan kemampuan utama guru, karena pembelajaran klasikal ini merupakan kegiatan belajar dan mengajar yang tergolong efisien. Dilakukan pendekatan dengan saintifik dengan pembelajaran yang masih berpusat pada guru namun dalam pembelajarannya memuat 5M. Model pembelajaran ini disebut dengan model pembelajaran klasikal dengan pendekatan saitifik dengan langkah-langkah yang dapat dilihat pada Tabel 1 
aktivitas belajar yang didorong oleh niat atau motivasi atau keterampilan tertentu dan siswa mempunyai tujuan dalam belajar untuk menguasai suatu kompetensi tertentu sehingga mampu menyelesaikan masalah yang sedang dihadapi. Adapun aspek-aspek SRL yang dapat diturunkan dari definisi kemandirian belajar ialah: (a) memiliki inisiatif belajar dari diri sendiri, (b) memiliki keteraturan belajar, (c) mampu menyelesaikan suatu masalah, (d) mampu menempatkan diri ke dalam lingkungan sosial. SRL dikelompokkan menjadi 3 kelompok, yaitu tinggi, sedang, dan rendah dengan pengelompokan skor angket diberikan pada Tabel 2. di bawah ini.

Tabel 2. Pengelompokan Skor Angket SRL

\begin{tabular}{ccc}
\hline No & Interval & Keterangan \\
\hline 1 & $X>\bar{X}+0,5 S$ & Tinggi \\
2 & $\bar{X}-0,5 S \leq X \leq \bar{X}+0,5 S$ & Sedang \\
3 & $X<\bar{X}-0,5 S$ & Rendah \\
\hline
\end{tabular}

Dengan : $X$ : nilai SRL tiap responden; $\bar{X}:$ ratarata dari nilai SRL seluruh sampel; $S:$ standar deviasi dari seluruh sampel.

\section{Variabel Moderator}

Variabel moderator adalah variabel yang mempengaruhi (memperkuat atau memperlemah) hubungan antara variable independen dengan dependen (Sugiyono. 2012). Menurut Indriantoro (1999: 63-68) variabel moderator adalah variabel yang dapat memperkuat atau memperlemah hubungan langsung antara variabel independen dengan variabel dependen. Variabel ini mempunyai pengaruh terhadap sifat atau arah hubungan antar variabel. Sifat atau arah hubungan antara variabel-variabel independen dengan variabel-variabel dependen kemungkinan positif atau negatif tergantung pada variabel moderatornya.

\section{METODE PENELITIAN}

Penelitian ini termasuk penelitian eksperimen dengan desain faktorial. Sugiyono (2012) menyatakan bahwa desain faktorial merupakan modifikasi dari design true experimental, yaitu dengan memperhatikan kemungkinan adanya variabel moderator yang mempengaruhi perlakuan terhadap hasil. Bentuk hubungan antar variabelnya digambarkan pada Gambar 1 berikut.

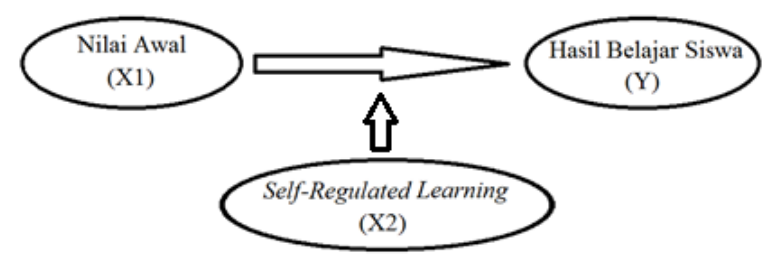

Gambar 1. Hubungan Antar Variabel dalam Penelitian

Populasi dalam penelitian ini adalah SMP negeri yang berada di Kabupaten Boyolali dan sudah menerapkan pembelajaran dengan kurikulum 2013. Teknik pengambilan sampel dengan simple random sampling. Penelitian dilakukan pada 31 siswa kelas VII A di SMP Negeri 3 Sawit Kabuaten Boyolali provinsi Jawa Tengah semester ganjil tahun ajaran 2014/2015. Variabel bebas dalam penelitian ini adalah pembelajaran klasikal dengan pendekatan saintifik. Variabel terikatnya adalah hasil belajar siswa. Sedangkan variabel moderatornya SelfRegulated Learning (SRL).

Metode pengumpulan data yang dilakukan adalah dengan metode dokumentasi, metode angket, dan metode tes. Metode dokumentasi adalah cara pengumpulan data dengan melihatnya dalam dokumen-dokumen yang telah ada (Budiyono. 2003). Dalam penelitian ini data nilai awal diperoleh dari nilai UN matematika Sekolah Dasar, yang 
selanjutnya digunakan untuk uji normalitas. Kemudian untuk mengetahui tingkatan SRL siswa digunakan metode angket dengan jenis angket langsung yang tertutup dengan skala Likert. Terdiri dari 30 pernyataan dalam angket yang terbagi menjadi item positif dan item negatif dengan 4 alternatif jawaban (sangat sesuai, sesuai, tidak sesuai, dan sangat tidak sesuai). Metode tes dilakukan untuk memperoleh data hasil belajar siswa, terdiri dari 30 soal matematika tentang bilangan.

Teknik analisis data yang digunakan untuk menguji variabel moderatornya dapat memperkuat hubungan antara variabel bebas dan terikatnya dengan menggunakan regresi linear sederhana atau Regression Analysis (RA) yang kemudian dilakukan uji interaksi yang merupakan aplikasi khusus regresi linear berganda atau Moderated Regression Analysis (MRA). Seperti yang dikemukakan oleh Liana (2009), MRA digunakan untuk pengujian variabel moderating terhadap hubungan antara variabel independen dan variabel dependen. MRA mengandung unsur interaksi yaitu perkalian dua atau lebih variabel independen pada persamaan regresinya yang merupakan aplikasi khusus regresi berganda linear.

\section{HASIL DAN PEMBAHASAN}

Penelitian ini terlebih dahulu dengan melakukan uji normalitas data nilai awal siswa yang diperoleh dari hasil nilai UN matematika dengan menggunakan uji KolmogorovSmirnov. Dilakukan uji dengan SPSS, diberikan hasil uji yang ditampilkan pada Tabel 3 berikut :

Tabel 3. Hasil Uji Normalitas Kolmogorov-Smirnov dengan SPSS

\begin{tabular}{llr}
\hline & & $\begin{array}{c}\text { Unstandardized } \\
\text { Residual }\end{array}$ \\
\hline $\mathrm{N}$ & Mean & 31 \\
Normal Parameters $^{\mathrm{a}}$ & Std. Deviation & .0000000 \\
Most Extreme Differences & Absolute & .86837760 \\
& Positive & .099 \\
& Negative & .099 \\
Kolmogorov-Smirnov Z & &. .063 \\
Asymp. Sig. (2-tailed) & & .553 \\
\hline a. Test distribution is Normal & .919 \\
\hline
\end{tabular}

Berdasarkan output di atas, diketahui bahwa signifikansi sebesar 0.919 lebih dari 0.05 , sehingga dapat disimpulkan bahwa data nilai awal berdistribusi normal. Setelah itu dilakukan pengujian variabel moderator dengan uji regresi linear sederhana kemudian variabel moderatornya dapat memberikan pengaruh positif atau negatif.

Dilakukan Regression Analysis (RA) dan Moderated Regression Analysis (MRA), diperoleh hasil seperti yang disajikan pada Tabel 4 dan Tabel 5 berikut.

dilanjutkan uji untuk mengetahui apakah

Tabel 4. Rangkuman Statistika Deskriptif

\begin{tabular}{lrr}
\hline Descriptive Statistics & \multicolumn{1}{c}{ Mean } & Std. Deviation \\
\hline Y (Hasil Belajar Siswa) & 3.5600 & .96018 \\
X1 (nilai UN Matematika) & 5.9113 & 1.27728 \\
X2 (SRL, variabel moderator) & 90.5161 & 4.93876 \\
X1.X2 & $5.3531 \mathrm{E} 2$ & 120.01642 \\
\hline
\end{tabular}


Tabel 5. Rangkuman RA dan MRA

\begin{tabular}{lcccccccc}
\hline & R & $\begin{array}{c}\text { R } \\
\text { Square }\end{array}$ & $\begin{array}{c}\text { Adjusted } \\
\text { R Square }\end{array}$ & $\begin{array}{c}\text { Std. Error } \\
\text { of the } \\
\text { Estimate }\end{array}$ & $\begin{array}{c}\text { F } \\
\text { Change }\end{array}$ & df1 & df2 & $\begin{array}{c}\text { Sig. F } \\
\text { Change }\end{array}$ \\
\hline RA & $.427^{\text {a }}$ & .182 & .154 & .88322 & 6.456 & 1 & 29 & .017 \\
MRA & $.630^{\text {a }}$ & .396 & .329 & .78636 & 5.910 & 3 & 27 & .003 \\
\hline
\end{tabular}

Nilai standart deviasai pada tabel 4 diperoleh sebesar 0.96018, sedangkan standart eror dari estimasi pada tabel 5 untuk RA sebesar 0.88322 dan untuk MRA sebesar 0.78636 lebih kecil dari standart deviasai. Oleh karena itu, model regresi linear (RA) maupun model regresi linear moderator (MRA) bagus dalam bertindak sebagai predictor hasil belajar.

Untuk model dalam RA pada tabel 5, sumbangan predictor sebesar $18.2 \%$. Nilai $\mathrm{F}$ sebesar $6.456(\mathrm{p}=0.017 ; \mathrm{p}<0.05)$, hal ini berarti nilai awal dapat memprediksi hasil belajar secara signifikan. Sedangkan untuk model MRA, sumbangan predictor sebesar 39.6\%. Nilai F sebesar 5.910 ( $p=0.003$; $p<$ 0.05 ), hal ini berarti bahwa nilai awal dengan SRL dapat memprediksi hasil belajar secara signifikan. Sumbangan predictor yang semula $18.2 \%$ (dari model RA) meningkat sebesar 21.4\% menjadi 39.6\% (dari model MRA), ini berarti bahwa nilai awal dengan SRL mampu memprediksi hasil belajar siswa.

SRL mampu memprediksi hasil belajar siswa karena siswa dengan tingkat SRL yang baik memiliki inisiatif belajar dari diri sendiri, teratur dalam belajar, mampu menyelesaikan suatu masalah dan dapat menempatkan diri ke dalam lingkungan sosial. Siswa dengan kemampuan tersebut mampu menyesuaian pembelajaran dengan pendekatan saintifik yang di dalam proses belajarnya terdapat proses mengamati, menanya, mengumpulkan data, menganalisis, dan mengkomunikasikan. Oleh karena itu SRL berperan memoderatori pembelajaran dengan pendekatan saintifik terhadap hasil belajar siswa.

Hasil penelitian di atas sejalan dengan penelitian yang dilakukan Zimmerman (1989) yang mengemukakan bahwa SRL dapat meningkatkan prestasi belajar dan akademik siswa, hal ini didorong karena tertarik mempelajari proses yang digunakan siswa untuk memulai dan mengarahkan usaha mereka agar memperoleh pengetahuan dan keterampilan. Samahalnya dengan penelitian yang dilakukan Sunawan dkk (2012), mengembangkan dan menguji efektivitas model bimbingan kesulitan belajar bagi siswa SMA berbasis SRL. Hasil penelitian didapati bahwa dengan mendorong siswa menerapkan SRL dalam belajarnya dapat membantu meningkatkan pola belajar siswa yang sejalan dengan prinsip SRL dan dapat meningkatkan prestasi belajar.

SRL terbukti efektif dalam jangka panjang untuk memelihara prestasi belajar mahasiswa pada pendidikan jarak jauh (Darmayanti, 2011). Jika keteladanan dan SRL digabungkan, terbukti efektif dalam jangka panjang untuk memelihara prestasi belajar mahasiswa pada pendidikan jarak jauh. Fasikhah dan Fatimah (2013) dalam penelitiannya meneliti tentang SRL, membandingkan dua kelompok mahasiswa yang diberikan pelatihan SRL dan yang satunya tidak. Diperoleh hasil bahwa kelompok yang diberi pelatihan SRL memiliki indeks prestasi akademik lebih tinggi dibandingkan kelompok yang tidak diberi pelatihan SRL. Sehingga dapat dikatakan bahwa pelatihan SRL 
memberikan pengaruh terhadap peningkatan terhadap peningkatan indeks prestasi akademik mahasiswa.

Dari beberapa hasil penelitian yang telah dilakukan, maka SRL itu penting dalam pembentukan sikap siswa untuk dapat memiliki kemandirian belajarnya. Hal ini juga didukung dengan penelitian yang dilakukan oleh Effeneya, dkk (2013) yang mengidentifikasi strategi pembelajaran SRL yang bersumber dari sembilan remaja berusia 15 sampai 17 tahun dengan melakukan wawancara semi terstruktur dengan peserta dan orang tua untuk mendapatkan informasi tentang strategi dan konteks SRL dalam pembentukan kebiasaan mengatur diri sendiri. Dalam penelitian ini, guru sebagai sumber strategi SRL yang paling umum dengan pengalaman penting yang terjadi selama dua tahun pertama di SMA.

Selain itu SRL juga dapat berperan untuk meningkatkan hasil belajar para peserta didik di karenakan pada siswa dengan tingkat SRL yang tinggi memiliki inisiatif belajar dan dapat memilih strategi belajarnya sendiri, sehingga dapat memberikan dampak perubahan positif terhadap pretest ke posttest. Greene dan Azevedo (2007) melakukan penelitian kepada remaja saat belajar tentang sistem peredaran darah dengan menggunakan hypermedia. Dalam penelitiannya mencari hubungan antara proses SRL dan perubahan mental siswa dari pretest ke posttest. Hasil penelitian menunjukkan bahwa terjadi perubahan pada peserta yang ditunjukkan melalui beberapa proses SRL, termasuk aktivitas pemantauan metakognitif, strategi pembelajaran, dan indikasi kesulitan tugas. Azevedo dan Cromley (2004) meneliti 131 mahasiswa tingkat sarjana tentang efektivitas SRL dalam memfasilitasi pembelajaran dengan hypermedia. Terdapat dua kelompok dengan diberikan perlakuan yang berbeda. Diperoleh hasil bahwa kelompok dengan kondisi SRL memfasilitasi pergeseran model mental peserta didik secara signifikan lebih banyak daripada kondisi kelompok yang tidak diberikan perlakuan apapun.

Alasan lain mengapa SRL dapat memberikan pengaruh positif dalam pembelajaran dengan pendekatan saintifik terhadap hasil belajar siswa juga diutarakan oleh Zimmerman, dkk (1996) dalam penelitiannya yang memberikan gambaran bagaimana siklus SRL dapat diterapkan untuk memungkinkan siswa sekolah menengah dan sekolah menengah atas mengembangkan 5 keterampilan akademis yang penting: (a) merencanakan dan menggunakan waktu belajar secara lebih efektif, (b) memahami dan meringkas materi teks yang lebih baik, (c) memperbaiki metode pencatatan, (d) mengantisipasi dan mempersiapkan yang lebih baik untuk ujian, dan (e) menulis lebih efektif. Sedangkan menurut Stone (2000), SRL adalah proses pengembangan tujuan, strategi, dan pemantauan kinerja untuk menyelesaikan tugas.

Berbeda dengan penelitian yang dilakukan oleh Cetin (2015). Cetin melakukan penelitian terhadap SRL dengan tujuan untuk mengetahui apakah motivasi akademik dan SRL dapat memprediksi IPK peserta didik di jurusan PAUD di Georgia Southern University, AS. Hasil penelitian menunjukkan bahwa tidak ada korelasi antara IPK dan motivasi akademik dan SRL. Dengan kata lain, motivasi akademik dan SRL tidak dapat memprediksi IPK. Hal ini disebabkan karena adanya beberapa faktor, yaitu kecerdasan, tingkat kesopanan, tingkat keseriusan dalam memilih jurusan PAUD, serta kebiasaan perilaku mahasiswa tersebut. Berbeda dengan penelitian yang dilakukan oleh Savira dan Suharsono (2013) yang meneliti tentang SRL 
dan prokastinasi akademik siswa kelas XI program akselerasi SMA Negeri di Kota Malang dengan usia 13-15 tahun. Mendapati siswa dengan prokrastinasi akademik tinggi adalah siswa yang menunda-nunda, terlambat mengumpulkaan tugas dan mendahulukan aktivitas lain saat menyelesaikan tugas. Sedangkan yang tergolong prokrastinasi akademik rendah adalah siswa yang tertib mengerjakan dan mengumpulkan tugas sesuia dengan waktu yang direncanakan serta fokus terhadap tugas yang ingin diselesaikan. Hasil peneltian diperoleh hasil bahwa terdapat hubungan negatif antara SRL dengan prokrastinasi akademiknya.

\section{KESIMPULAN}

Berdasarkan hasil dan pembahasan di atas didapati bahwa SRL memberikan sumbangan sebesar $21.4 \%$ dalam peningkatan hasil belajar siswa, sehingga SRL dapat memberikan pengaruh positif dalam pembelajaran dengan pendekatan saintifik terhadap hasil belajar siswa. SRL mampu memprediksi hasil belajar siswa karena siswa dengan tingkat SRL yang baik memiliki inisiatif belajar dari diri sendiri, teratur dalam belajar, mampu menyelesaikan suatu masalah dan dapat menempatkan diri ke dalam lingkungan sosial. Siswa dengan kemampuan tersebut mampu menyesuaian pembelajaran dengan pendekatan saintifik yang di dalam proses belajarnya terdapat proses mengamati, menanya, mengumpulkan data, menganalisis, dan mengkomunikasikan. Oleh karena itu SRL berperan memoderatori pembelajaran dengan pendekatan saintifik terhadap hasil belajar siswa.

Hasil penelitian ini memberikan gambaran kepada peneliti dan guru tentang salah satu cara untuk meningkatkan hasil belajar siswa dalam pembelajaran dengan pendekatan saintifik, yaitu dengan meningkatkan SRL siswa. Penelitian ini diharapkan untuk menjadi sumbangan pemikiran dalam meningkatkan inisiatif belajar dari diri sendiri, teratur dalam belajar, tetap berusaha menyelesaikan suatu masalah dan menempatkan diri ke dalam lingkungan sosial yang merupakan aspek dari SRL. Diharapkan pula hasil penelitian ini dapat menjadi sumbangan pemikiran atau pengetahuan dalam merancang dan memperhatikan tentang pentingnya SRL yang dapat memoderatori pembelajaran dengan pendekatan saintifik terhadap hasil belajar siswa SMP.

\section{UCAPAN TERIMA KASIH}

Terimakasih kepada Prof. Dr. Slameto, M.Pd yang telah membimbing penulis dalam menyelesaikan artikel ini.

\section{DAFTAR PUSTAKA}

Asrori, M. 2008. Psikologi Pembelajaran. Bandung : Wacana Prima: 129.

Azevedo, R., \& Cromley, J. G. 2004. Does Training on Self-Regulated Learning Facilitate Students' Learning With Hypermedia? Journal of Educational Psychology. Vol 96. No 3. pp 523535.

Budiyono. 2003. Metodologi Penelitian Pendidikan. Surakarta: UNS Press :54

Cetin, Baris. 2015. Academic Motivation and Self-Regulated Learning in Predicting Academic Achievement in College. Journal of International Education Research - Second Quarter. Vol 11. No 2. Pp 95-106.

Darmayanti, Tri. 2011. Studi Jangka Panjang tentang Efektivitas Intervensi Psikologis dalam Meningkatkan Kemampuan Belajar Mandiri dan Prestasi Belajar Mahasiswa Pendidikan Jarak Jauh. Jurnal 
Pendidikan Terbuka dan Jarak Jauh. Vol 12. No 1.

Dimyati dan Mudjiono. 2006. Belajar dan Pembelajaran. Jakarta: Rineka Cipta : 169-170

Effeneya, G, Carrollb, A \& Bahrc, N. 2013. Self-Regulated Learning: Key Strategies and Their Sources In A Sample Of Adolescent Males. Australian Journal of Educational \& Developmental Psychology. Vol 13. 2013. pp. 58-74.

Fasikhah, S. S dan Fatimah, S. 2013. SelfRegulated Learning (SRL) dalam Meningkatkan Prestasi Akademik pada Mahasiswa. Jurnal Ilmiah Psikologi Terapan. Vol 1. No 1.

Ferla, J. 2008. The Effect of Student Cognitions about Learning on SelfRegulated Learning: A Study with Freshmen in Higher Education. Proefschrift ingediend tot het behalen van de academische graad van Doctor in de Pedagogische Wetenschappen. University Gent. Tesis.

Greene, J. A., \& Azevedo, R. 2007. Adolescents' use of Self-Regulatory Processes and Their Relation to Qualitative Mental Model Shifts While Using Hypermedia. Journal of Educational Computing Research. Vol 36. No 2. pp 125-148.

Hadi, S. 2010. Analisis Kemampuan Komunikasi Matematika Melalui Model Thimk Talk Write (TTW) Peserta Didik SMPN 1 Manyar Gresik. Jurnal Pendidikan Matematika. Vol.1, No.2, pp 52-59.

Hosnan. 2014. Pendekatan Saintifik dan Kontekstual dalam Pembelajaran Abad 21. Kunci Sukses Implementasi Kurikulum 2013. Bogor : Ghalia Indonesia.
Indriantoro,N. dan B. Supomo. 1999. Metodologi Penelitian Bisnis untuk Akuntansi \& Manajemen. Edisi Pertama. Yogyakarta: BPFE : 63-68.

Liana, Lie. 2009. Penggunaan MRA dengan SPSS untuk Menguji Pengaruh Variabel Moderating terhadap Hubungan antara Variabel Independen dan Variabel Dependen. Jurnal Teknologi Informasi DINAMIK. Vol. XIV, No.2, Juli. pp 90-97.

Montalvo, F. T and Maria C. G. T. 2004. SelfRegulated Learning : Current and Future Direction. Electronic Journal of Research in Educational Psychology. Vol 2. No 1. pp 1-34.

Paris, S G. 2001. Classroom Aplications of Research on Selft-Regulated Learning. Educational Psychologist. Vol.36, No.2, pp 89-101.

Sagala, S. 2010. Konsep dan Makna Pembelajaran. Bandung : Alfabeta.

Savira, F dan Suharsono, Y. 2013. SelfRegulated Learning (SRL) dengan Prokrastnasi Akademik pada Siswa Akselerasi. Jurnal Ilmiah Psikologi Terapan. Vol 1. No 1. pp 66-75.

Stone, N. J. 2000. Exploring the relationship between calibration and self-regulated learning. Educational Psychology Review. Vol 12. No 4. pp 437-475.

Sugiyono. 2012. Metode Penelitian Kombinasi (Mixed Methods). Bandung: Alfabeta. 64-65, 114-115

Sugiyono. 2012. Statistika untuk Penelitian. Bandung: Alfabeta: 114-115

Sui, E and Ho,C. 2004. Self-Regulated Learning and Academic Achievement of Hong Kong Secondary School Students. Education Jurnal. Vol.32, No.2, pp 87-107.

Sumarmo, U. 2010. Kemandirian Belajar: Apa, Mengapa dan Bagaimana 
Dikembangkan Pada Peserta Didik. Jurnal FMIPA pascasarjana UPI. Diunduh dari math.sps.upi.edu/?p=61. Diakses pada tanggal 15 April 2014.

Sunawan, Sugiharto, D.Y.P., Anni, C.T. 2012. Bimbingan Kesulitan Belajar Berbasis Self Regulated Learning dalam Meningkatkan Prestasi Belajar Siswa. Jurnal Ilmu Pendidikan. Vol 18. No 1. pp 113-124.

Vrieling, E. 2012. Effects of Increased SelfRegulated Learning Opportunities on StudentTeachers' Motivation and Use of Metacognitive Skills". Australian Journal of Teacher Education. Vol. 37, Page 102-117
Zimmerman, B. J. 1989. A Social Cognitive View of Self-Regulated Academic Learning. Journal of Educational Psychology. Vol 81. No 3. pp 329339.

Zimmerman, B. J., Bonner, S., \& Kovach, R. 1996. Developing Self-Regulated Learners: Beyond Achievement to Self-Efficacy. American Psychological Association.

Zumbrunn, S., Tadlock, J., Roberts, E. D. 2011. Encouraging Self-Regulated Learning in the Classroom: A Review of the Literature. Metropolitan Educational Research Consortium (MERC), Virginia Commonwealth University. pp 1-28. 